\title{
CANCER INFORMATION FOR CHILDREN: EFFECT ON ADHERENCE TO INTRAMUSCULAR CHEMOTHERAPY
}

\author{
CANCER INFORMATION FOR CHILDREN: EFFECT ON ADHERENCE TO \\ INTRAMUSCULAR CHEMOTHERAPY
}

\author{
Mariana Amaral', Maria Rita Zoéga Soares² y Paula Suzana Gioia' \\ I Pontifícia Universidade Católica de São Paulo, São Paulo, Brasil \\ 2 Universidade Estadual de Londrina, Londrina, Brasil (UEL)
}

Abstract

Objective. The purpose of this study was to verify the effects of an intervention that involved providing cancer information to children. The intervention targeted children's adherence to treatment as well as competing behaviors that interfered with the chemotherapy.

Method. A 9-year-old girl and a 4-year-old boy participated in the study, both diagnosed with acute lymphoblastic leukemia and undergoing ambulatory chemotherapy. The participants' chemotherapy sessions were filmed before, during and after intervention, in a total of 16 sessions. The intervention, carried out individually for each participant throughout three sessions, was based on the book Estou doente, e agora? Orientações para crianças com câncer (I'm ill, what now? Orientations for children with cancer), which was organized into 24 cards containing information, recreational activities and other exercises for expressing feelings about the illness and its treatment. The recordings were watched by blind observers who recorded the occurrence of adherence and competing responses, both defined in accordance with an adapted version of the Observation Scale of Behavioral Distress (OSBD).

Results. The results showed that the intervention was effective. During intervention,
Resumen

Objetivo. Evaluar los efectos de una intervención para informar a los niños sobre el cáncer. Se pretendió mejorar la adhesión al tratamiento y conductas concurrentes que interfieren con la quimioterapia.

Método. Participaron una niña y un niño de 9 y 4 años respectivamente, diagnosticados con leucemia linfoblastica aguda y en tratamiento en el ambulatorio de quimioterapia. Los participantes fueron filmados antes, durante y después de la intervención, en un total de 16 sesiones. La intervención psicológica ha sido realizada con cada participante en tres sesiones individualmente, basada en el libro Estou doente e agora? Orientacoes para criancas com cancer (Estoy enfermo y ahora? Orientaciones para niños con cáncer), organizada en 24 fichas conteniendo información, actividades recreativas y otros ejercicios de expresión de sentimientos sobre la enfermedad y el tratamiento. El registro filmado fue analizado por observadores ciegos que identificaron la ocurrencia de respuestas de adhesión y concurrentes, definidos de acuerdo con una version adaptada de la Observation Scale of Behavioral Distress (OSBD).

Resultados. Los resultados muestran que la intervención fue efectiva. Durante la intervención la frecuencia de comportamientos de

\section{Correspondencia:}

Adressee: Mariana Amaral

Laboratório de Psicologia Experimental

Programa de Estudos Pós Graduados em Psicologia Experimental: Análise do Comportamento PUC-SP (PEXP)

Rua Bartira, 387 - Bairro: Perdizes - CEP: 05009-000 - São Paulo, SP - Brazil

E-mail: marianaamaral@hotmail.com 
the frequency of the children's adherence behaviors increased, while the frequency of their competing behaviors decreased. However, these effects were not maintained in post-intervention sessions.

Conclusions. This is an intervention model that can be the basis for new studies attempting to plan increasingly better contingencies in order to develop a behavioral repertoire that is adaptive to this condition. The future studies should use a larger number of sessions and participants and adopt group interventions.

Keywords: Adherence behavior, cancer, children, information. adhesión, se ha incrementado y la de comportamientos concurrentes, ha disminuido. No obstante tales efectos no se mantuvieron en las sesiones pos intervención.

Conclusiones. Este es um modelo de intervención que debe ser analizado en otros estudios que busquen mejorar las contingencias para el desarrollo de un repertorio conductual que auxilie en la adaptación a esa condición. Los estudios futuros deberían usar un mayor número de sesiones, de participantes y grupos de control.

Palabras clave: Comportamiento de adhesión, cáncer, niños, información.

\section{INTRODUCTION}

Childhood cancer is the second biggest cause of death by illness in children both in the world and in Brazil, where it is responsible for $7 \%$ of total deaths. The Brazilian National Cancer Institute ${ }^{(1)}$ estimated that in 2015 there were 11,840 new cases of the illness in children and adolescents in the country. In the last four decades, there have been significant advances in oncology and in the treatment of childhood cancer. It is estimated that $70 \%$ of children with the illness, if diagnosed early and treated in specialized health centers, can be cured and have a good quality of life ${ }^{(1)}$.

The most common therapies for the illness involve surgeries, transplants, chemotherapy and radiation therapy. All require specific care and cause acute side effects, such as nausea, vomiting, pain, among others. In addition, oncological treatment requires changes in the family's routine and in the child's lifestyle habits ${ }^{(1)}$. Thus, childhood cancer care should go beyond medical treatment. "Psychosocial support" (interventions targeting children while considering cognitive, emotional and social aspects) should be given from the moment the diagnosis is made and during the entire treatment ${ }^{(2)}$, always with the goal of guaranteeing the patient the best quality of life possible. For this purpose, doctors, nurses, psychologists and other healthcare professionals should be involved in the process ${ }^{(1)}$.

Several of the difficulties faced by oncological patients could be the focus of psychologists' interventions, such as physiological responses of anxiety, interpersonal skills deficit, and poor adherence to treatment ${ }^{(2)}$. For the behavior analyst, such problems are understood as behaviors that can be modified if their controlling variables are changed.

Oftentimes an aggravating factor in cancer treatment is its length, which requires that radical changes be made to an individual's daily routine. According to the World Health Organization (WHO) (3), adherence to long-term treatments, as in the case of cancer, can be defined as the extent to which a person's behavior conforms to the recommendations made by health professionals, such as taking medication, following a diet, or changing one's lifestyle. The $\mathrm{WHO}^{(3)}$ also states that non-adherence is the main cause of a treatment's decreased effectiveness and 
can lead to medical complications of the illness, reduction in the patient's quality of life, and a rise in the financial costs of healthcare, among other outcomes. When it comes to cancer, behaviors incompatible with adherence to treatment include inconsistent use of prescribed medication, failure to attend medical appointments, and the absence of necessary self-care behaviors, such as a balanced diet and adequate hygiene ${ }^{(4)}$.

Aside from these behaviors, with regards to the child cancer patient, adherence should also include collaborative behaviors during medical procedures, which should facilitate the performance of such procedures. It could be said, therefore, that several different responses emitted in different contexts are defined as adherence, since together they produce the common consequence of improving the treatment's effectiveness.

However, for adherence to occur, incompatible behavior should cease. In the context of an invasive procedure, children oftentimes express displeasure and anger, as well as verbal refusal to submit themselves to treatment, possibly due to a previous history of exposure to this aversive event of a painful and invasive nature. This reaction from the child makes it difficult for healthcare professionals to carry out the medical procedure. When facing opposition from the child, it is common for the medical team and caretakers to adopt punitive measures, such as voice raising and physical restraint. The child, who is incapable of avoiding or escaping the situation, will be subjected to an increase in the intensity and in the duration of this aversive contingency. From this perspective, the occurrence of adherence behaviors, to the detriment of competing behaviors, will benefit the child patient, the medical team whose work is made easier, and the parents who will not be exposed to the increased suffering of their child. Furthermore, a situation in which the child emits adherence behaviors can positively affect other patients, leading to reduced tension in the hospital environment, with less discomfort caused by the child's shouting and crying.

With regards to measuring collaborative behaviors during medical procedures, one can mention the work $^{(5)}$ which created an adaptation of the Observation Scale of Behavioral Distress (OSBD) that defines adherence as well competing behaviors that prevent, delay or hinder an invasive procedure. Currently, the adaptation of the OSBD scale ${ }^{(5)}$ allows for the measurement of the frequency of adherence and competing behaviors during the performance of invasive medical procedures on chronic pediatric patients $^{(6-7)}$.

Research about procedures, in general, can be summarized in literature reviews. Regarding adherence to treatments of chronic illnesses, a meta-analysis ${ }^{(8)}$ indicated that the main interventions with this target involve strategies that can be categorized into four types. The first involves "educational" strategies or procedures, which are characterized by teaching or providing information about the illness. The second type includes "behavioral" procedures, thus called because they are based on behavior analysis techniques for teaching new skills, as in parent training and teaching problem solving. There are also "organizational" procedures, which focus on the organizational system and on changing healthcare, such as the creation of support groups for healthcare teams. The last type refers to "multi-component interventions".

Of particular interest to the present study is the intervention based on providing information to child cancer patients. In pediatric psycho-oncology, interventions that precede the medical procedure can 
involve the provision of preparatory and descriptive information about what will take place and about how to behave in that situation. Information is one of the main facilitators of adherence behavior and can be provided through books, audiovisual resources, recreational activities, storytelling or through the simulation of real situations ${ }^{(9)}$.

To inform is to present antecedent verbal stimuli that can be the occasion for the emission of certain responses, even those that have never before been emitted. Verbally-governed behavior may be closely linked to the behavioral pattern of adherence. Success and failure in adherence to treatments have been a concern for healthcare professionals.

The advantage of verbally-governed behavior, especially in the context of healthcare, is the possibility of teaching new repertoires quickly, without the need for a lengthy process of shaping behavior. When a doctor tells a patient to take medication at certain times, for example, this rule can control the response of taking medication in that manner, without the patient having to go through the aversive consequences produced by not following the prescribed treatment. Another advantage of verbally-governed behavior is the possibility of teaching responses whose consequences are delayed or the opposite of the immediate consequences ${ }^{(10)}$. Chemotherapy treatment is a clear example of this: its immediate consequences are aversive (side-effects), but it could also save the patient's life in the long term.

The literature points out some advantages of presenting patients with information about therapeutic procedures for the illness ${ }^{(11)}$. Information about the disease and about the workings of the human organism is a necessary condition for the child cancer patient to be able to acquire coping skills and, thus, become an active participant in clinical decisions regarding the illness and its treatment. Being informed promotes a greater sense of security and helps reduce anxiety, consequently facilitating one's commitment to the treatment. This concern led to the creation of informative yet recreational materials with the aim of promoting educational procedures in healthcare ${ }^{(12)}$. The book, Estou doente, e agora? Orientações para crianças com câncer (I'm ill, what now? Orientations for children with cancer), describes cancer and chemotherapy treatment and is organized into 24 cards containing facts, pictures and activities ${ }^{(12)}$. The authors believed that this resource could promote knowledge about the disease but did not propose a structured method of using it.

The present study sought to verify the effect of a procedure, based on the book Estou doente, e agora? Orientações Para crianças com câncer ${ }^{(12)}$ on adherence and competing behaviors emitted by children who underwent chemotherapy given by intramuscular injection. The authors hypothesize that the procedure will produce an increase in adherence behaviors and a decrease in incompatible behaviors, and that these changes will be maintained one month after the end of the intervention.

\section{METHOD}

\section{Participants}

Two children undergoing ambulatory chemotherapy treatment were selected to participate in the study based on the referral of the sector's psychologist. Two years before the start of the study, Child 01 (female, 9 years of age) had begun treatment for acute lymphoblastic leukemia. Child 02 (male, 4 years of age) had been in treatment for the same illness for 2 years and 6 months. Chemotherapy was administered via intramuscular injections in weekly sessions. 
Both participants were chosen after the OSBD scale results indicated that competing behaviors occurred during the invasive medical procedure in at least three consecutive chemotherapy sessions.

\section{SETTING}

The study was carried out in the Ambulatory Chemotherapy Sector of a public hospital in the city of Londrina (Paraná, Brazil). In each intervention session, the researcher and the participant faced each other while seated in children's chairs and shared a table on which the activities were carried out. No specific location in the hospital was reserved for these activities. Therefore, the researcher carried a plastic table to wherever there was space and a certain level of privacy. The locations used for the study were the Psychology sector, the front hall and the employee exit.

\section{MATERIALS}

The intervention was based on the book Estou doente, e agora? Orientações Para crianças com câncer ${ }^{(12)}$, which provides basic information about cancer and tumors, including the concept of cells, information about routines, exams, hospitalization, the surgical center, specific pathologies and treatment. The information is divided into cards and presented to the child through texts, pictures, activities and games. This material also includes activities that provide ways for the child to express physiological sensations and emotional states.

In the present study, the only cards used were those deemed suitable for the participants: A1 - Introduction, B2 - Cancer (Informative), C2 - Exams (Informative), C3 - Activity: Game about routine, D1 - Definitions / Side-effects (Informative), D2 - Activity: "Dress yourself" (for female patients) or D3 - Activity: "Dress yourself" (for male patients), D4 - Activity: Adherence Behaviors, D5 - Activity: Tips for reducing side-effects, E2 - Activity: Drawing, E3 Activity: Card for a friend. The cards that dealt with specific pathologies were not used.

The adapted version ${ }^{1}$ of the OSBD Scale ${ }^{(5)}$, was used for the behavioral evaluation. The instrument is composed of behavioral categories that include operationally defined verbal, vocal and motor responses emitted during the exposure to the invasive medical procedure. According to this version of the scale, adherence behaviors include responses that do not hinder and/or tend to facilitate the performance of the invasive medical procedure: Talk; Answer Orally; Information Seeking; Seek Emotional Support, Look, Look at Another Stimulus, and Help Perform the Medical Procedure. Competing behaviors include responses that hinder, delay or prevent the performance of the invasive medical procedure: Whimper, Cry, Nervous Behaviors, Physically Attack, Scream, Move to the Point of Restraint, Escape, and Verbal Resistance. The operational definition of each response in this version of the OSBD scale can be found in Table 1.

\section{PROCEDURE}

In this study, video recordings of the chemotherapy sessions were used in order to allow for the systematic observation of the frequency of adherence and competing behaviors before, during and after intervention.

1 A non validated, translated from English to Portuguese version of the original scale, used for research purposes. Reference of the original scale: Elliot, C. H., Jay, S. M., \& Woody, P. (1987). An Observation Scale for Measuring Children's Distress During Medical Procedures. J. Pediatr. Psychol. 1987,12(4),543551. doi: 10.1093/jpepsy/12.4.543. 
Table 1. Definitions of adherence and competing behaviors used in the study

DEFINITION OF ADHERENCE AND COMPETING BEHAVIORS

\begin{tabular}{|c|c|c|}
\hline \multicolumn{3}{|c|}{ ADHERENCE } \\
\hline Behavior & Description & Example \\
\hline Talk & $\begin{array}{l}\text { Verbalization emitted during the procedure that does not include } \\
\text { any type of objection to the invasive procedure }\end{array}$ & $\begin{array}{c}\text { "it's very hot today" } \\
\text { or } \\
\text { "I like this game" }\end{array}$ \\
\hline Answer Orally & $\begin{array}{l}\text { Verbalization emitted in response to a verbal stimulus emitted by a } \\
\text { person present during the invasive procedure }\end{array}$ & $\begin{array}{l}\text { "Hello, how are } \\
\text { you?" } \\
\text { (nursing assistant) } \\
\text { "I'm fine" (child) }\end{array}$ \\
\hline $\begin{array}{l}\text { Information } \\
\text { Seeking }\end{array}$ & Solicitation of information about the procedure & "Will it hurt?" \\
\hline $\begin{array}{l}\text { Seek Emotional } \\
\text { Support }\end{array}$ & $\begin{array}{l}\text { Solicitation of hugs, kisses, caretaker's lap or any other type of } \\
\text { physical comfort from another person }\end{array}$ & $\begin{array}{l}\text { "Mother, give me a } \\
\text { hug" or } \\
\text { "Auntie, hold my } \\
\text { hand" }\end{array}$ \\
\hline Look & Looking at the execution of the invasive procedure & \\
\hline $\begin{array}{l}\text { Look at Another } \\
\text { Stimulus }\end{array}$ & $\begin{array}{l}\text { Looking towards another stimulus or situation and not at the } \\
\text { execution of the invasive medical procedure }\end{array}$ & \\
\hline $\begin{array}{l}\text { Help Perform the } \\
\text { Medical Procedure }\end{array}$ & $\begin{array}{l}\text { Behavior that indicates participation in carrying out the invasive } \\
\text { medical procedure }\end{array}$ & $\begin{array}{l}\text { "Use the vein on } \\
\text { my left arm so I can } \\
\text { draw with my right" }\end{array}$ \\
\hline \multicolumn{3}{|c|}{ COMPETING } \\
\hline Behavior & Description & Example \\
\hline
\end{tabular}

Whimper

Cry

Nervous Behavior

Physically Attack

Scream

Move to the Point

of Restraint

Escape

Verbal Resistance
Please, cut the extra space off sounds typical mutterings in the absence of tears, of low intensity, intersected by pauses

Sounds of low or moderate intensity accompanied by tears and intersected by pauses

Physical manifestations consisting of small, quick and repeated actions

Motor behaviors that cause damage to another person present in the situation

High intensity sounds without the emission of words

Intense movements of the body that require an external agent to exert enough physical force to restrain it

Leaving the location before beginning or finishing the invasive medical procedure

Verbalization indicating refusal to comply with the invasive medical procedure or indicating pain
Biting fingernails, biting lips, tapping fingers, hands or feet, or hitting head against the chair

Biting, hitting, pinching and kicking

Leaving the procedure room

"Stop!", "I don't want this!" or "Ouch, it hurts!" 
Before data collection began, two video cameras were placed in the infusion room for the duration of three weeks in order to guarantee that employees, patients and caretakers would adapt to the presence of the equipment.

The procedure was divided into three phases.

In the first phase - Baseline - video recordings were made from the moment the nurse approached the child (who was generally accompanied by his/ her mother or another caretaker) to administer the medication (injection). The recording stopped at the end of the medical procedure, when the nurse or the child left the room. Video was recorded individually for each child. After each of the blind observers observed the child's behaviors in the video, he/she recorded them on a standardized recording sheet containing the categories identified in the adapted version of the OSBD scale.

After baseline sessions ended (four sessions for Child 01 and five sessions for Child 02), Phase 2 began - Intervention - which consisted of three sessions averaging 1 hour each. The intervention procedure consisted of reading to the child in a manner that he/she could follow. After reading, comments were made about the pictures, and pauses were taken to discuss each paragraph so as to verify the child's comprehension about what was read. When possible, the researcher asked the child to talk about his/her experience as an oncological patient and about how this related to what was read. Play activities using materials from the book (games, cards and coloring pictures) were carried out while the child waited for the chemotherapy procedure.

The aim of the first session was to establish a rapport with the child and to invite him/her to participate in the study. In addition, information about cancer, exams and the hospital routine were provided.
For this, specific cards from the book were used with the following pre-established goals:

- A1 - to inform the child about the activities that would be carried out, letting him/her interact with the materials, and about the times and days of the sessions;

- B2 - to inform the child about cancer by explaining what the illness is, how it originates, and where it can appear in the human body;

- $\mathrm{C} 2$ - to present to the child the purpose of the exams that he/she should undergo, detailing how they work and what the procedures would be like;

- C3 - to provide playtime with a board game that showed the routine the child experienced every time they arrived at the hospital, including laboratory exams, waiting, the doctor's appointment, and some important behaviors for his/her health during treatment.

To conclude the session, the child was requested to describe what was addressed during the session. The activities ended with the presentation of the themes that would be explored in the next session, when the patient would return for another application of chemotherapy.

In the second session, the goal was to inform the child about the purpose of the chemotherapy medications, how they are administered, the side-effects, as well as how to care for one's health during treatment. The following cards were used, each with a specific objective:

- D1 - to inform about chemotherapy medications (function, route of administration, and side-effects);

- D2 and D3 - to show the main physical change caused by the 
medications (hair loss) and possible clothing and accessory choices to deal with this condition;

- D4 - to show, through pictures, what cares should be taken during treatment.

The session's conclusion was similar to that of the first session.

In the third and last session, the aim was to allow the child to report feelings about his/her condition through drawings, messages, painting etc. The following cards were used, each with a specific objective:

- D5, D6, and D7 - to inform about one of the discomforts of chemotherapy (dry mouth), and to ask the child to express how he/ she feels about the medication sideeffects by drawing and writing;

- E3 - to ask the child to create a card for a friend who undergoes chemotherapy, and to write about feelings and expectations about the friend's recovery. The child was asked to create a drawing that showed how he/she felt about the treatment at that moment.

Finally, the researcher concluded the procedure by saying goodbye to the children, returning their drawings, and recommending that they continue the activity during the following weeks while in the waiting room or during the chemotherapy procedures. It was not verified whether the participants later carried out this activity.

The third phase of the study aimed to verify whether possible behavioral changes occurring during intervention would be maintained post-intervention. Both participants' chemotherapy sessions continued to be filmed until Week 16 of the study.

\section{Experimental design}

The study was conducted using a multiple baseline design across participants. This type of design allows the evaluation of irreversible behavioral effects of an intervention. Two or more behaviors are simultaneously observed until the intervention is inserted, in different moments of the procedure for each participant. If the behavior patterns of the participants begin to change only with the beginning of an intervention, it is assumed that those changes are resultant of the manipulations made by the intervention, and not by any other external variables along time ${ }^{(13)}$. The multiple baseline across participants is an alternative of research design to increase the validity of the conclusions of studies with few participants.

In the present study, the intervention began at different times for each participant - in the fifth session for Child 01 (two baseline sessions) and in the seventh session (four baseline sessions) for Child 02.

\section{Reliability of the observation record}

The video recordings were observed by four previously trained blind judges, who recorded adherence and competing behaviors in the standardized recording sheet from the adapted version of the OSBD scale. The minimum accepted level of interrater agreement was $85 \%$, calculated by the formula ${ }^{(14-15)}$ : $\%$ of Interrater Agreement $=$ (number of concordances / number of concordances + number of disagreements) X 100.

\section{RESULTS}

The results showed that the procedure of informing participants about cancer and its treatment was effective in that it increased the percentage of adherence behaviors and decreased competing behaviors. 
As seen in Figure 01, Child 01 showed an increase in the frequency of adherence behaviors during intervention $(68 \%$ of behaviors emitted during that phase) in relation to baseline (56\%). The occurrence of these adherence behaviors continued to increase in frequency in the post-intervention evaluation (85\%). The frequency of occurrence of competing behaviors was greater during the preintervention phase (44\%), decreased during the intervention sessions (32\%), and continued to decrease post-intervention (15\%). For Child 01, therefore, the intervention had the effect of increasing adherence and decreasing competing behaviors in both the intervention and post-intervention phases.

Child 02 showed an increase in the frequency of occurrence of adherence behaviors during the intervention phase $(85 \%)$ in relation to the pre-intervention phase (7\%). After these phases, occurrence of these behaviors decreased $(11 \%)$, although it remained at a higher percentage than during pre-intervention.
On the other hand, competing behaviors occurred at a high frequency in the preintervention phase (93\%), suffered a sharp decline during intervention (15\%), and increased once more in the postintervention period $(89 \%)$. It is important to note that this frequency was lower than the one recorded in baseline. It is possible to conclude, therefore, that, for Child 02, the intervention had a positive effect on the increase of adherence behaviors and decrease of competing behaviors during the intervention stage, but there was a tendency for these behaviors to return to baseline levels post-intervention.

It is important to describe the type of adherence or competing behavior emitted by the participants throughout the study. For Child 01, different adherence behaviors occurred in greater frequency during intervention in comparison to baseline: Talk (six responses observed in baseline and 15 in intervention), Answer Orally (1/2), Seek Emotional Support (14/19), Look (1/3), Look at Another Stimulus (2/4), and Help Perform the Medical Procedure

\section{Figure 1. Percentage of adherence and competing behaviors emitted by the participants in each phase}

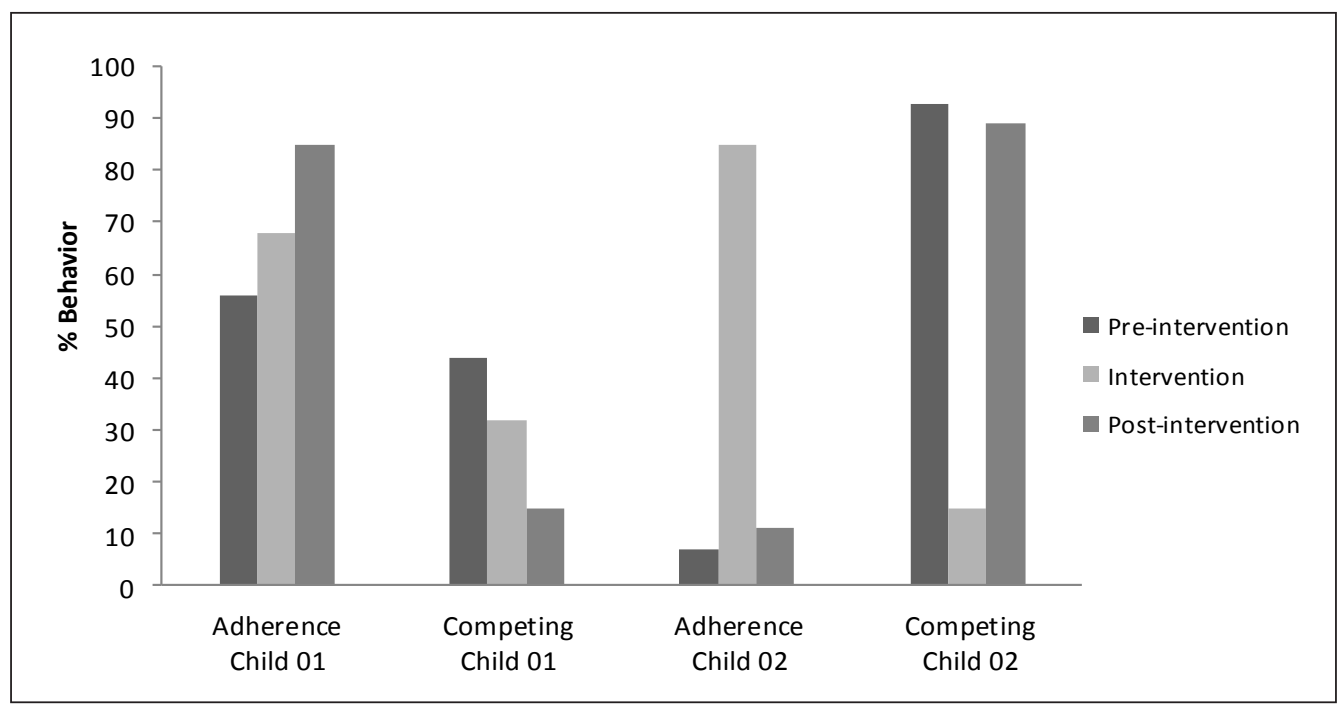


$(0 / 1)$. After intervention, the frequency of some of these responses decreased: Talk (nine responses observed postintervention), Answer Orally (1), Seek Emotional Support (17), and Look (1). The adherence response of Look at Another Stimulus was not observed in this phase, and Help Perform the Medical Procedure occurred at the same frequency as in intervention (one occurrence). The only adherence behavior category that was not observed in any phase of the procedure was Information Seeking.

In relation to competing behaviors for Child 01, the biggest change occurred in the category Cry, since this response was observed five times in baseline and was not at all observed during intervention. The competing behaviors with total frequency of occurrence higher or equal to that in baseline were Whimper (five responses in baseline and five in the intervention phase), Nervous Behaviors (5/9), and Verbal Resistance (4/7). It is important to consider that, on the day before Session 07, one of the children in treatment, a friend of the participant, passed away. This situation may have possibly led to the increased frequency of competing behaviors. This event could have been the condition for the occurrence of a different behavioral pattern, in which most of the competing behaviors from the intervention phase were emitted: Whimper (five in Session 07), Nervous Behaviors (5), and Verbal Resistance (5). Physically Attack, Scream, Move to the Point of Restraint, and Escape were not observed in any phase of the study.

Thus, results show that, for Child 01, the intervention seems to have favored an increase in the emission of Talk and Seek Emotional Support. The procedure may also have helped in decreasing the response Cry in the intervention and post-intervention phases and in decreasing the frequency of Whimper, Nervous Behaviors and Verbal Resistance in the post-intervention phase.
Child 02 presented a different response pattern from that of Child 01. The adherence behaviors that increased in frequency during intervention, in comparison to baseline, were Talk (zero responses were observed in baseline and five in intervention), Answer Orally (2/3), Seek Emotional Support (2/8), Look (2/3), and Look at Another Stimulus (0/3). However, these results were not maintained in the post-intervention phase: Talk (no responses were observed post-intervention), Answer Orally (2), Seek Emotional Support (3), Look (0), and Look at Another Stimulus (0). Information Seeking and Help Perform the Medical Procedure were not observed in any phase during the study.

The competing responses whose frequency decreased during the intervention phase, in comparison to baseline, were Whimper (seven responses in baseline and none during intervention), Cry (16/0), Nervous Behaviors (16/2), Physically Attack (6/0), Scream (14/0), Move to the Point of Restraint (16/0), and Verbal Resistance $(11 / 2)$. However, these responses were emitted in greater frequency in the postintervention period: Whimper (one response in post-intervention), Cry (8), Nervous Behaviors (8), Physically Attack(2), Scream (10), Move to the Point of Restraint (9), and Verbal Resistance (5). Only one competing response, Escape, stopped being emitted by this participant during both the intervention and post-intervention phases. In conclusion, therefore, it seems that the intervention was effective for Child 02 in increasing adherence and decreasing competing behaviors. However, during the chemotherapy sessions in the postintervention phase, the frequency of adherence behaviors decreased once again, and that of the competing behaviors increased.

To help analyze the effect of the intervention on the participants' responses in each session throughout the study, Figure 


\section{Figure 2. Percentage of adherence and competing} behaviors in each session of the study

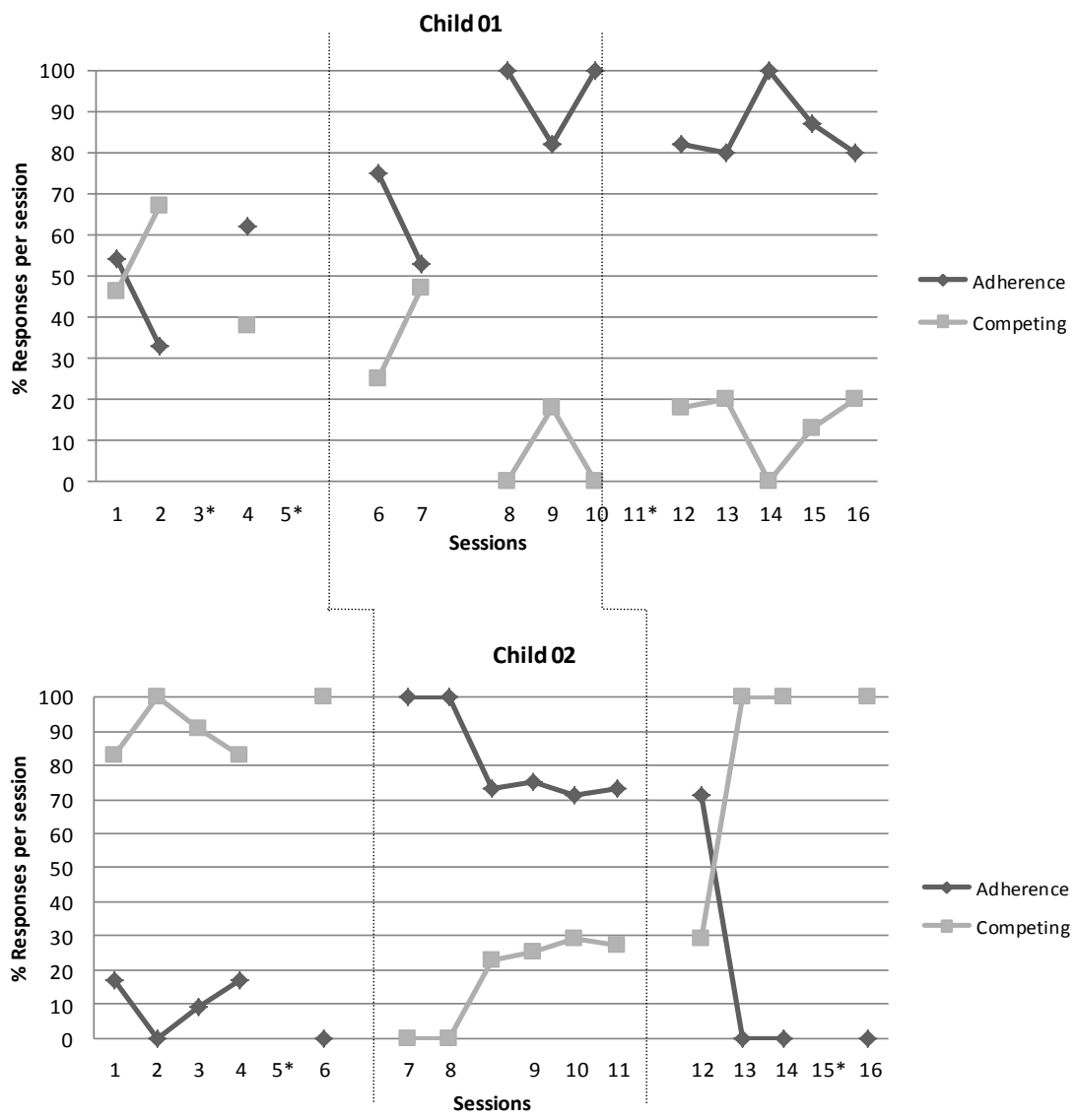

${ }^{(*)}$ Sessions in which the participant did not show up at the hospital for the administration of the chemotherapy drug.

2 presents the percentage of responses that occurred per session for each participant. During baseline, the percentages for Child 01, for both adherence and competing behaviors, did not stabilize throughout the sessions. Despite this, the intervention was still carried out due to the conditions of the treatment. During the intervention, it was possible to observe that, in the majority of the sessions, Child 01 presented a greater percentage of adherence behaviors to the detriment of competing behaviors, seeing as $75 \%$ of the total behaviors emitted in
Session 06 were adherence behaviors, $53 \%$ in Session 07, 100\% in Session 08, $82 \%$ in Session 09, and $100 \%$ in Session 10. In the post-intervention phase, Child 01 also presented a higher percentage of adherence behaviors in comparison to competing behaviors: $82 \%$ of behaviors in Session 12 were adherence behaviors, $80 \%$ in Sessions 13 and 14, 100\% in Session 15 , and $87 \%$ in Session 16. There was no data for Sessions 3, 5 and 11 because the child did not show up at the hospital for the chemotherapy procedure. 
Figure 2 also shows Child 02's performance in the different phases of the study. During baseline, the participant emitted a low frequency of adherence behaviors in comparison to competing behaviors. In Session 01, 17\% of total behaviors were categorized as adherence. These behaviors were not observed in the second baseline session. In the third session, adherence behaviors comprised $9 \%$ of total emitted behaviors, $17 \%$ in Session 4, and 0\% in Session 6. However, during intervention, these numbers underwent a sudden change - Child 02 began to emit a considerably higher percentage of adherence behaviors in relation to competing behaviors. Adherence behaviors comprised $100 \%$ of the total in Sessions 07 and 08, 75\% in Session 09, $71 \%$ in Session 10, and $73 \%$ in Session 11. In the post-intervention phase, with the exception of Session 12, the percentage of adherence behaviors decreased abruptly in relation to the competing behaviors in each session. In Session 12, 71\% of total behaviors were adherence behaviors. In Sessions 13, 14 and 16, the child did not emit any adherence behaviors, being that $100 \%$ of the registered behaviors were of the competing type. No data was recorded for Sessions 05 and 15 due to the child's absence from the chemotherapy procedure.

Although the behavioral patterns for both children were different during baseline, after analyzing the occurrence of target behaviors during intervention, both participants predominantly emitted adherence behaviors as compared to competing behaviors. In the postintervention period, however, this predominance was only maintained in the case of Child 01, seeing as Child 02 showed an abrupt decrease in the percentages of adherence behaviors and consequent increase in competing behaviors.

\section{DISCUSSION}

The present intervention had positive effects on the participants' behavior, such as increasing the frequency of adherence behaviors and decreasing competing behaviors. Increasing patients' knowledge about their condition, by means of accessible information combined with playful strategies, may increase the probability of these children actively participating in their treatment, thus strengthening adherence behaviors to the detriment of competing ones ${ }^{(16)}$. Therefore, this is an intervention model that can be the basis for new studies attempting to plan increasingly better contingencies in order to develop a behavioral repertoire that is adaptive to this condition. This strategy can be considered a relevant intervention proposal in the context of healthcare, especially in Pediatric PsychoOncology.

The high frequency of competing behaviors emitted by both participants before intervention shows that the context of this invasive procedure had acquired the function of evoking behaviors related to displeasure and anger in children and to the refusal to submit to the chemotherapy treatment. These behaviors arise as a product of aversive contingencies of a painful and invasive nature, to which the children were exposed during their treatment. The behaviors that compete with adherence may be maintained by way of negative reinforcement, since they generally produce the temporary delay or removal of the aversive medical procedure (which did in fact occur in that environment), as well as by attention from adults (parents and healthcare staff) who try to calm down the child. However, the occurrence of collaborative behaviors in the hospital setting is important, for without them treatment cannot possibly occur. 
The purpose of the present study was to verify whether providing cancer information to children in chemotherapy would be effective in increasing adherence behaviors. The information provided in the proposed intervention could have controlled the emission of adherence behaviors, which was verified by the increase in frequency of these behaviors during the chemotherapy sessions that occurred immediately after reading and talking about the invasive procedures. This type of cooperation could contribute to a decrease in the treatment's duration and complexity, leading to the amelioration of symptoms and of the illness itself ${ }^{(5)}$. Nonetheless, the maintenance of this new pattern of responding did not occur for both children in the post-intervention period.

In the case of Child 02, the fact that competing behaviors, incompatible with adherence, returned to baseline levels may indicate that environmental control was limited solely to the intervention of providing information contained in the book. The social variables present in the context of chemotherapy may not have selected the adherence behaviors and may not, therefore, have been sufficient to maintain the new behaviors. These variables probably had the function of strengthening competing behavior, since these responses proved to occur frequently after the child underwent a high number of chemotherapy sessions (Child $01-2$ years, Child $02-2$ and a half years).

Therefore, a limitation of the present study was not including the parents who accompanied their children during treatment. By adopting certain educational practices, parents can provide adequate consequences to adherence responses at the moment they occur, during the medical procedure, and can alter their future probability of occurrence. In this perspective, new studies should involve parents of children undergoing chemotherapy, focusing on the management of consequences to behaviors emitted by the children. Aside from parents, this condition could include caretakers and health workers. In this manner, the establishment and maintenance of behaviors would occur with both evocative and reinforcing contingencies - in other words, with the presentation of antecedent verbal stimuli as well as consequent verbal stimuli with a positively reinforcing function, so as to guarantee that behaviors would be maintained in the future.

The authors suggest that future studies use a larger sample of participants during a longer period of investigation in order to increase the generality of results between participants and over time. Another suggestion was based on the verbal reports of the participants themselves, who suggested that the program be applied in a group format. For these children, the activities would have been more fun had they been carried out with other children. This illustrates the importance of implementing group interventions in health institutions, that have the additional advantage of social reinforcement contingencies acting upon the acquisition of new behavioral patterns.

Finally, healthcare professionals could also, in a general manner, act in ways to alter a patient's behaviors during invasive medical procedures, since their actions are part of the contingencies present in this context. Therefore, studies should seek to evaluate and provide effective models of intervention for professionals who work in pediatric oncological services. Programs should train these professionals to apply behavioral techniques, seeking to develop abilities that help patients face medical procedures $^{(6)}$.

\section{REFERENCES}

1. Instituto Nacional do Câncer José Alencar Gomes da Silva. Tipos de Câncer: Infantil [Internet]. www2.inca.gov.br. 2016 [cited 
5 July 2016]. Available from: http://www2. inca.gov.br/wps/wcm/connect/tiposdecancer/site/home/infantil.

2. Mavrides N, Pao, M. Updates in pediatric psycho-oncology. Int Rev Psychiatry 2014;26:63-73. Doi: 10.3109/09540261.2013.870537

3. World Health Organization. Adherence to long-term therapies: Evidence for action. [Internet]. World Health Organization. 2003 [cited 5 July 2016]. Available from: http://www.who.int/chp/knowledge/publications/adherence_introduction.pdf

4. Robertson EG, Wakefield CE, Marshall KH, Sansom-Daly UM. (2015). Strategies to improve adherence to treatment in adolescents and young adults with cancer: A systematic review. J Clin Oncol 2010;5:3549. Doi: http://dx.doi.org/10.2147/COAYA.S85988.

5. Costa Junior AL. Análise de comportamentos de crianças expostas à punção venosa para quimioterapia [Doctor's Degree]. Universidade de Brasília; 2001.

6. Lemos IP, Ferreira EAP. Comportamento de crianças, acompanhantes e auxiliares de enfermagem durante sessão de punção venosa. Psic Teor e Pesq 2010;23:433-43. Doi: 10.1590/S010237722010000300006.

7. Oliveira FPS, Ferreira EAP, Novaes VR, Lima, JS. Análise do comportamento de crianças vítimas de queimaduras expostas a curativo sem sedação em enfermaria. Rev Bras Crescimento Desenvolv hum 2009;19:369-82.
8. Graves, M. M., Roberts, M. C., Rapoff, M., $\&$ Boyer, A. The efficacy of adherence interventions for chronically ill children: A metaanalytic review.JPediatr Psychol 2010;35:36882. Doi: 10.1093/jpepsy/jsp072.

9. Soares MRZ, Amaral M. Livro de Histórias: Uma proposta de intervenção com o paciente oncológico infantil. In: Wielenska RC, organizer. Sobre Comportamento e Cognição - Desafios, soluções e questionamentos. Santo André: ESETec, 2009, p. 132-5.

10. Skinner BF. Contingencies of reinforcement: A theoretical analysis. New York: Appleton-Century-Crofs, 1969.

11. Soares MRZ, Sabião LS, Orlandini, TF. A criança hospitalizada: A importância da informação. Pediatr Mod 2009;45:156-9.

12. Casanova LT, Soares, MRZ. Estou doente, e agora? Orientações para crianças com câncer. Londrina: EdUEL, 2009.

13. Velasco, SM, Garcia-Mijares, M, Tomanari, GY. Fundamentos metodológicos da pesquisa em análise experimental do comportamento. Psicol Pesq 2010;4:150-5.

14. Hartmann, DP. Considerations in the choice of interobserver reliability estimates. J Appl Behav Anal 1977;10:103-16. Doi: 10.1901/jaba.1977.10-103.

15. House, AE, House, BJ, Campbell, MB. Measures of interobserver agreement: Calculation formulas and distribution effects. J Behav Assess 1981;3:37-57. Doi:10.1007/ BF01321350.

16. Alder B, Porter M, Abraham C, Teijlingen E. Psychology and sociology applied to medicine. London: Churchill Livingstone, 2004. 